\title{
USE OF COMPLEMENTARY AND ALTERNATIVE MEDICINE BY CANCER PATIENTS AT ZHEJIANG UNIVERSITY TEACHING HOSPITAL ZHUJI HOSPITAL, CHINA
}

\section{Lisong Teng ${ }^{1}$, Ketao Jin ${ }^{1,2}$, Kuifeng $\mathrm{He}^{1}$, Chunge $\mathrm{Bian}^{2}$, Weili Chen ${ }^{2}$, Kaiyan $\mathrm{Fu}^{2}$, Tieming $\mathrm{Zhu}^{2}$, Zhigang Jin $^{2}$}

\author{
${ }^{1}$ Department of Surgical Oncology, the First Affiliated Hospital, College of Medicine, Zhejiang \\ University, Hangzhou, Zhejiang Province, 310003, P.R. China. \\ ${ }^{2}$ Department of Surgical Oncology, Zhuji Hospital, Zhuji, Zhejiang Province, 311800, P.R. China \\ * E-mail: jinketao2001@yahoo.com.cn
}

\begin{abstract}
Complementary and alternative medicine (CAM) is garnering increasing interest and acceptance among the general population throughout the world. The use of CAM by cancer patients is very common in China. The referenced English literature has no rural community-based study from China on this subject. This study was conducted to define the prevalence, pattern of use, and reasons for using CAM by cancer patients at Zhejiang University Teaching Hospital Zhuji Hospital (ZUTH-ZJH), China. Face-to-face interviews using a structured questionnaire were used to determine the use of CAM by cancer patients. All consenting cancer patients were interviewed as they presented at the Department of Surgical Oncology of ZUTH-ZJH, from September 2009 to February 2010. One hundred and twenty one patients were interviewed; 64 (52.9\%) were males and $57(47.1 \%)$ were females. One hundred and thirteen patients (93.4\%) have used CAM at some time during their current cancer illness, fifty two (46.0\%) are female and sixty one (54.0\%) are male patients; $8(6.6 \%)$ patients have not used any form of CAM. Chinese medicine (73.5.0\%) was the most commonly reported CAM modality. Over $71.7 \%$ of those who used CAM were satisfied, only $28.3 \%$ were disappointed. Twenty eight users (24.8\%) did not see any benefit from the CAM, but eighty one patients $(71.7 \%)$ could describe some specific benefits. Only one patient will use orthodox medicine instead of CAM in the future, almost all patients will continue to use CAM in the future. CAM use is very common among cancer patients in local area of China. Most users obtain the expected benefits, and adverse events are uncommon. It is imperative that oncologists should explore the use of CAM with their cancer patients and work towards an integrated model of health-care provision. This knowledge will enable oncologists to better counsel the patients.
\end{abstract}

Key words: complementary and alternative medicine, cancer, China

\section{Introduction}

Complementary and alternative medicine (CAM) has been defined as 'any diagnosis, treatment or prevention that complements mainstream medicine by contributing to a common whole, by satisfying a demand not met by orthodoxy or by diversifying the conceptual framework of medicine' (Ernst et al., 1995; Ernst, 1995). CAM includes a wide range of therapies. The National Center for Complementary and Alternative Medicine in the USA classifies CAM therapies into five categories (National Center for Complementary and Alternative Medicine, 2004): alternative medical systems, such as traditional Chinese medicine or Ayurveda; mind-body interventions, such as meditation, prayer, healing or support groups; biologically based therapies, such as herbs, dietary supplements or vitamins; manipulation and body-based methods, such as massage, chiropractic or osteopathy; and energy therapies, such as Qi Gong, Reiki, and magnetic fields).

The use of CAM has increased steadily over the past decades, and it has gained medical, economic and sociological importance in Western countries (Ernst and Cassileth, 1998). However, as the bulk of the literature comes from 
the Western countries (Oneschuk et al., 1998; Kelly et al., 2000; Richardson et al., 2000; Sparber, et al., 2000; Bernstein and Grasso, 2001; Cassileth et al., 2001; Jordan and Delunas, 2001; Patterson et al., 2002; Swisher et al., 2002; Molassiotis and Cubbin, 2004), little is known about the use of CAM in cancer patients specifically in rural area of China. The aim of the present study was to assess the prevalence, pattern of use, and reasons for using CAM by cancer patients at Zhejiang University College of Medicine Teaching Hospital Zhuji Hospital (ZUTH-ZJH), China.

\section{Patients and methods}

Patients and settings

This was a cross-sectional study involving the direct administration of questionnaires to all cancer patients seen at the Department of Surgical Oncology of ZUTH-ZJH, from September 2009 to February 2010. Patients were included if they met the following inclusion criteria: they were adult patients of either gender with a diagnosis of cancer; aware of their diagnosis; able to understand the questions; free from any condition that would make completing the questionnaire inappropriate or overburdening for the patients; and they were willing to participate in the study.

\section{Procedures}

Three interviewers (nurses) were trained to administer the questionnaire throughout the study. The questionnaire was anonymous and was handed out to the patients after they received information about the study, agreed to participate and signed the consent form. Patients completed the questionnaire while they were resting at the wards to be seen by the nurses. On completion, patients handed the questionnaire to the nurse. The patients were informed that they were free to decline answering any question with which they were not comfortable. Physicians who were in any way involved in the treatment of each patient were not present during the interview.

\section{The questionnaire}

The questionnaire used was based on the one developed by Swisher et al (Swisher et al., 2002). However, the questionnaire was modified for the purposes of the present study. The questionnaire included demographic data, such as age, sex, marital status, socioeconomic status, occupation, insurance coverage, and highest level of education attained. Questions were asked about the type of cancer, previous treatments received, and the treatment that the patient was currently receiving. If patients reported no past or current use of CAM during their cancers after completing the demographic and clinical section of the questionnaire, they were thanked for their contribution and asked to stop completing the questionnaire at that stage. If patients reported past or current use of CAM during their cancers, they were asked to continue.

In the rest of the questionnaire, each patient was presented with a list of known CAM remedies. The patient was asked whether he/she had used any of them during his/her cancer. Patients who had used CAM at least once during the study were regarded as CAM users; non-users had not used CAM at all during his/her cancer. Those who had used CAM previously in their lives but not currently using were also considered nonusers. CAM practices and therapies presented to the patients included: alternative medical systems (Chinese medicine, acupuncture, homeopathy, ritual sacrifice, divination/incantations, specified folk remedies, et al); mind-body interventions (massage, manual healing/therapeutic touch, mind-body technique, hypnosis, visualization/vision, meditation, and faith healing/prayer house healing, etc), biologically-based treatments (herbal drugs, high dose/mega vitamins, forever living products, aloe vera, medicinal tea, green tea, special diets/nutritional therapies, mineral therapy, animal extracts, python fat, etc), manipulative and body-based methods (bloodletting/coup, chiropractics, osteopathy/bone setting, et al) and energy therapy (bioelectromagnetics, oxygen therapy, et al). CAM users were asked how frequently they used CAM, how they got the provision about the CAM, what 
useful effect they were hoping to get from CAM (reasons for using CAM), how they had actually benefited from the CAM, what ill effects or side-effects they suffered from using the reported CAM therapy, and how much money they had spent on CAM therapy. They were asked if they had discontinued or hoped to discontinue CAM. Finally, the patients were asked whether their doctor knew they were using or had used CAM, and whether they perceived any impediments to discussing their use of CAM freely with their doctor.

\section{Statistical analysis}

The data were analyzed using Statistical Package for Social Sciences (SPSS) software version 16.0. Descriptive statistics were calculated with all variables to summarize the data. Difference between reasons for using CAM and perceived benefits from its use was assessed using the Chi-square test.

\section{Results}

Demographic and clinical characteristics of the sample

One hundred and twenty five patients were invited to participate in the study. One hundred and twenty one patients (96.8\%) patients were interviewed; 64 (52.9\%) were males and 57 (47.1\%) were females. One hundred and thirteen patients (93.4\%) have used CAM at some time during their current cancer illness; fifty two (46.0\%) were female and sixty one (54.0\%) were male patients. Their mean age was 57.31 years [range 19-85; standard deviation (SD) 12.78]. Patient's demographic and clinical characteristics are outlined in Table 1. Lung, gastric, breast, colorectal, and liver cancers predominated.

\section{The prevalence and patterns of CAM use}

Table 2 shows the patterns and prevalence of CAM therapies used by cancer patients. One hundred and thirteen patients (93.4.0\%) reported having used at least one form of CAM therapy after cancer diagnosis; 8 (6.6\%) patients have not used any form of CAM. Chinese medicine (73.5.0\%) was the most commonly reported CAM modality. Sixteen patients used psychological techniques such as faith healing (14.2\%).

The most common provider of CAM was traditional Chinese medicine doctors (38.1\%) followed by family members $(33.6 \%)$ and friends $(24.8 .0 \%)$. Fifty eight patients $(51.3 \%)$ visited a CAM provider once a month and fourteen patients (12.4\%) visited a CAM provider 1-2 times a week. Furthermore, thirty two patients (28.3\%) visited a CAM provider almost daily. Eighty four patients (74.3\%) using CAM had informed their oncologist and believed it was important information for their oncologist to know. Twenty nine patients $(25.7 \%)$ did not mention their use of CAM to their doctors, mostly because the doctor did not ask.

\section{Reasons for using CAM and perceived benefits from its use}

We further examined patients' reasons for using CAM therapy and their perceived benefits experienced by the use of CAM therapy (Table 3). Most patients were using CAM as they wanted to increase their body's ability to fight the disease or to assist the body's natural forces to heal or to boost body's immune system (44.2\%), directly treat or cure the cancer or decrease tumor (38.1\%), improve physical well-being or increase quality of life (29.2\%), or relieve cancer symptoms (26.5\%). However, the benefits from using CAM didn't satisfy the patients' reasons for using CAM. In more detail, although the primary reason stated for using CAM was to increase the ability to fight the cancer, only twenty patients (17.7\%) found CAM of benefit $(\mathrm{P}<0.001)$. And although the reason stated for using CAM was to directly treat or cure the cancer, only seven 
Table 1: Demographic and clinical characteristics of the samples

\begin{tabular}{|c|c|c|c|}
\hline Parameter & & $\mathbf{n}$ & $\%$ \\
\hline \multirow[t]{2}{*}{ Sex } & Male & 61 & 54.0 \\
\hline & Female & 52 & 46.0 \\
\hline \multirow[t]{4}{*}{ Marital status } & Married & 104 & 92.0 \\
\hline & Single & 2 & 1.8 \\
\hline & Widowed/ Divorce/ Separated & 7 & 6.2 \\
\hline & No response & 0 & 0 \\
\hline \multirow[t]{4}{*}{ Education level } & Illiterate & 2 & 1.8 \\
\hline & Primary education & 55 & 48.7 \\
\hline & Secondary education (high school) & 52 & 46.0 \\
\hline & College/University education & 4 & 3.5 \\
\hline \multirow[t]{3}{*}{ Annual income of family (RMB) } & Low income $(<50,000)$ & 48 & 42.5 \\
\hline & Middle income $(50,000-100,000)$ & 21 & 18.6 \\
\hline & High income $(>100,000)$ & 44 & 39.0 \\
\hline \multirow[t]{7}{*}{ Occupation } & Retired & 19 & 16.8 \\
\hline & Educational profession & 2 & 1.8 \\
\hline & Managerial profession & 6 & 5.3 \\
\hline & Manual worker & 12 & 10.6 \\
\hline & Housewife & 14 & 12.4 \\
\hline & Peasant & 58 & 51.3 \\
\hline & Unemployed & 2 & 1.8 \\
\hline \multirow[t]{13}{*}{ Primary Cancer } & Lung cancer & 26 & 23.0 \\
\hline & Gastric cancer & 18 & 15.9 \\
\hline & Breast cancer & 16 & 14.2 \\
\hline & Colorectal cancer & 16 & 14.2 \\
\hline & Liver cancer & 12 & 10.6 \\
\hline & Gynecological cancers & 7 & 6.2 \\
\hline & Hematological cancers & 5 & 4.4 \\
\hline & Pancreatic cancer & 5 & 4.4 \\
\hline & Head and neck caner & 4 & 3.5 \\
\hline & Genitourinary cancers & 1 & 0.9 \\
\hline & Bone/spine cancer & 1 & 0.9 \\
\hline & Malignant melanoma & 1 & 0.9 \\
\hline & Brain tumors & 1 & 0.9 \\
\hline \multirow[t]{7}{*}{ Past treatment received } & Surgery alone & 19 & 16.8 \\
\hline & Chemotherapy & 20 & 17.7 \\
\hline & Radiotherapy & 0 & 0 \\
\hline & Surgery and chemotherapy & 52 & 46.0 \\
\hline & Chemotherapy and radiotherapy & 6 & 5.3 \\
\hline & Surgery, chemotherapy and radiation & 3 & 2.7 \\
\hline & Other combinations & 13 & 11.5 \\
\hline \multirow[t]{2}{*}{ Currently receiving treatment } & Surgery alone & 0 & 0 \\
\hline & Chemotherapy & 60 & 53.1 \\
\hline
\end{tabular}


Table 1 Continued: Demographic and clinical characteristics of the samples

Parameter

Radiotherapy
2

Surgery and chemotherapy

Chemotherapy and radiotherapy

Surgery, chemotherapy and radiation

Other combinations n $\%$

1.8

$0 \quad 0$

$5 \quad 4.4$

$0 \quad 0$

$46 \quad 40.7$

patients $(6.2 \%)$ found CAM of benefit $(\mathrm{P}<0.001)$. Additionally, it is interesting to note that forty four patients $(38.9 \%)$ found CAM to be helpful in relieving cancer symptoms, although this was only identified as a reason for use in $26.5 \%$ of the sample $(\mathrm{P}<0.05)$.

Over $71.7 \%$ of those who used CAM were satisfied, only $28.3 \%$ were disappointed. Twenty eight users $(24.8 \%)$ did not see any benefit from the CAM, but eighty one patients (71.7\%) could describe some specific benefits. Only one patient will use orthodox medicine instead of CAM in the future, almost all patients will continue to use CAM in the future.

\section{Ill effects or side-effects from using CAM therapy}

As shown in Table 4, eight patients (7.1\%) reported side-effects from the CAM therapy they had used. Most seemed to be transient side-effects and they were all related to ingesting herbs. These side-effects included stomach aches; gastric upset and nausea; itching; headaches and migraine; and diarrhoea.

\section{Discussion}

To the best of our knowledge, this is the first community-based study of the use of CAM therapies by cancer patients from rural area of China. Up-to-now, only Cui et al. (2004) and Chen et al. (2008) reported the use of CAM by cancer patients in China. Both of the studies assessed the prevalence, pattern of use, and reasons for using CAM by breast cancer patients. The patients included in the two studies were both from urban Shanghai but not from rural area of China.

The prevalence of CAM use among all cancer patients varies widely. Figures have ranged from 7\% to 83\% (Ernst and Cassileth, 1998; Sparber and Wootton, 2001), but the average rate across adult studies has been $31.4 \%$ (Ernst and Cassileth, 1998). Our own prevalence rate of $93.4 \%$ is one of the highest reported in the literature. While the definition of what is considered CAM therapy in each study accounts for some of these variations, we hypothesized that the high prevalence rate among our patients might be explained by the traditional nature of our society, the Chinese cultural and religious beliefs and practices, and the high cost of western conventional treatment. Though there is no English literature from mainland of China which can support our hypothesis, the finding of Roth and Kobayashi (2008) might give us some evidence. Their finding indicated that cultural factors played a key role in establishing the necessary conditions for increasing the likelihood of CAM use for Chinese Canadians. The high prevalence rate of CAM use in mainland of China may also partially due to the high insurance coverage of CAM. In China, especially in Zhejiang province, there is a sound 'Cooperative Medical System', medical expenses of using CAM has a compensation rate of $40 \%$ of total medical cost, while compensation rate for Western medicine is $20 \%$.

In our study, the most commonly used form of CAM in China is Chinese medicines and specified folk remedies, followed by faith healing/prayer house healing. Notwithstanding the current emphases on Western medicine in China, CAM is still one of the mainstream ways to treat diseases and ailments for many Chinese cancer patients. While the two systems 
Table 2: Patterns of CAM used by patients $(n=113)$

\begin{tabular}{|c|c|}
\hline Alternative medical systems & Frequency of use $n(\%)$ \\
\hline Chinese medicine & $83(73.5)$ \\
\hline Specified folk remedies & $22(19.5)$ \\
\hline Divination/incantations & $10(8.8)$ \\
\hline \multicolumn{2}{|l|}{ Mind-body interventions } \\
\hline Faith healing & $16(14.2)$ \\
\hline Prayer house healing & $8(7.1)$ \\
\hline Healing or support groups & $6(5.3)$ \\
\hline Autogenic training & $4(3.5)$ \\
\hline Psychic therapies & $1(0.9)$ \\
\hline Relaxation therapy & $1(0.9)$ \\
\hline Tai Chi & $1(0.9)$ \\
\hline \multicolumn{2}{|l|}{ Biologically-based therapies } \\
\hline Forever living products & $51(45.1)$ \\
\hline Special diets/nutritional therapies & $36(31.9)$ \\
\hline Herbs & $16(14.2)$ \\
\hline $\begin{array}{l}\text { Dietary supplements (animal extracts/ coenzyme Q10/ } \\
\text { Python fat) }\end{array}$ & $10(8.8)$ \\
\hline Medicinal tea & $5(4.4)$ \\
\hline Aloe vera & $2(1.8)$ \\
\hline Vitamins & $1(0.9)$ \\
\hline Green tea & $1(0.9)$ \\
\hline Aromatherapy & $1(0.9)$ \\
\hline Oxygen therapy & $1(0.9)$ \\
\hline \multicolumn{2}{|l|}{ Manipulation and body-based methods } \\
\hline Massage & $2(1.8)$ \\
\hline Tui-na & $1(0.9)$ \\
\hline Energy therapies & $0(0)$ \\
\hline \multicolumn{2}{|l|}{ CAM providers } \\
\hline Traditional Chinese medicine doctors & $43(38.1)$ \\
\hline Western medicine doctors & $4(3.5)$ \\
\hline Family members & $38(33.6)$ \\
\hline Friends or others & $28(24.8)$ \\
\hline
\end{tabular}

run parallel in the Chinese environment, switching from one form to the other is a common phenomenon and depends on which of them is more suitable for a particular condition. Just as Fan and Holliday (2007) suggested that a proper integrative system for CAM and Western medicine should be a dual standard based system in which both CAM and Western medicine are free to operate according to their own medical standards. In addition, most of Chinese cancer patients die even after receiving conventional western medical treatment. This gives people the impression that conventional western medical treatments may be not better than CAM. Subsequently, it makes sense for them to try CAM first or second, or to use CAM in combination with Western medicine to get all the benefits possible.

Conflicting findings have been reported about factors that affect the use of CAM therapies (Ernst and Cassileth, 1998; Sparber, et al., 2000; Jordan and Delunas, 2001; Swisher et al., 2002; Molassiotis and Cubbin, 2004). With respect to 
Table 3: Reasons for using CAM therapy and benefits experienced by the use of CAM therapy $(n=113)$

\begin{tabular}{|c|c|c|c|c|c|c|}
\hline Reasons for using CAM therapy & $\mathbf{n}$ & $\%$ & $\begin{array}{l}\text { Benefits experienced by the use of } \\
\text { CAM therapy }\end{array}$ & $\mathbf{n}$ & $\%$ & $p$ \\
\hline $\begin{array}{l}\text { To boost or increase body's ability to } \\
\text { fight cancer / To assist the body's } \\
\text { natural forces to heal / To boost } \\
\text { body's immune system }\end{array}$ & 50 & 44.2 & $\begin{array}{l}\text { Boosted or increased body's ability } \\
\text { to fight cancer / Assisted the body's } \\
\text { natural forces to heal / Boosted } \\
\text { body's immune system }\end{array}$ & 20 & 17.7 & $\mathrm{a}$ \\
\hline 'Might help, can't hurt' & 46 & 40.7 & No hurt & 47 & 41.6 & $\mathrm{~b}$ \\
\hline $\begin{array}{l}\text { To decrease tumor / To directly } \\
\text { treat/cure the cancer }\end{array}$ & 43 & 38.1 & Decreased tumor & 7 & 6.2 & a \\
\hline $\begin{array}{l}\text { To improve physical well being/ To } \\
\text { increase quality of life }\end{array}$ & 33 & 29.2 & $\begin{array}{l}\text { Improved physical well being/ } \\
\text { Increased quality of life }\end{array}$ & 25 & 22.1 & $\mathrm{~b}$ \\
\hline To relieve cancer symptoms & 30 & 26.5 & Relieved cancer symptoms & 44 & 38.9 & c \\
\hline Requested by physician & 25 & 22.1 & & & & \\
\hline Perfectly safe & 22 & 19.5 & & & & \\
\hline $\begin{array}{l}\text { To improve psychological and } \\
\text { emotional well being, provide hope } \\
\text { and increase optimism }\end{array}$ & 17 & 15.0 & $\begin{array}{l}\text { Improved psychological and } \\
\text { emotional well being, provided hope } \\
\text { and increased optimism }\end{array}$ & 17 & 15.0 & $\mathrm{~b}$ \\
\hline $\begin{array}{l}\text { To prevent spread of cancer/ To } \\
\text { prevent recurrence of cancer }\end{array}$ & 10 & 8.8 & & & & \\
\hline To assist other treatments & 9 & 8.0 & Assisted other treatments & 3 & 2.7 & $\mathrm{~b}$ \\
\hline $\begin{array}{l}\text { Desire to do everything possible to } \\
\text { fight the disease }\end{array}$ & 3 & 2.7 & & & & \\
\hline No response & 0 & 0 & No response & 1 & 0.9 & $\mathrm{~b}$ \\
\hline
\end{tabular}

${ }^{\mathrm{a}}, \mathrm{P}<0.001 ;{ }^{\mathrm{b}}, \mathrm{P}>0.05 ;{ }^{\mathrm{c}}, \mathrm{P}<0.05$.

Table 4: Ill effects or side-effects from using CAM therapy $(n=113)$

\begin{tabular}{lll}
\hline Ill effects or side-effects & $\mathbf{n}$ & $\mathbf{\%}$ \\
\hline No side-effects or uncomfortable feeling & 102 & 90.3 \\
With side-effects but hope to continue CAM treatment & 7 & 6.2 \\
With obvious side-effects and hope to discontinue CAM treatment & 1 & 0.9 \\
No response & 3 & 2.7 \\
Stomach aches & 3 & 2.7 \\
Gastric upset and nausea & 2 & 1.8 \\
Itching & 1 & 0.9 \\
Headaches and migraine & 1 & 0.9 \\
Diarrhoea & 1 & 0.9 \\
\hline
\end{tabular}

other CAM surveys in rural settings, for example, Ben-Arye E et al (Ben-Arye, et al., 2009) reported that women used CAM more often than men did and Jewish women used CAM more often than Arab women did. While we found there was no association between use of CAM and age, marital status, or socioeconomic status in our patients. Most of our patients expected CAM to increase their body's ability to fight the disease or to assist the body's natural forces to heal or to boost body's immune system $(44.2 \%)$, to directly treat or cure the cancer or decrease tumor $(38.1 \%)$, to improve physical well-being or increase quality of life (29.2\%), or to relieve cancer symptoms (26.5\%).CAM users in China mainly rely on 
CAM doctors for their information about CAM. Patients seem to be satisfied with the use of CAM, even if they do not see any obvious benefit from it. A wide range of reasons contribute to the use of CAM, and perhaps the concept of 'hope' is fundamental in each one of these reasons. Those who used CAM to improve physical and emotional well-being seemed to have benefited from CAM. These findings coincide with findings from the USA (Swisher et al., 2002).

Only $7.1 \%$ of patients reported ill effects or side-effects from CAM which supported the assumption that these agents are safe. In other side, it is very difficult to distinguish from the natural manifestations or progression of advanced cancers.

Some of our patients $(25.7 \%)$ who used CAM did not tell their doctors about it. The fact that these patients will not disclose their use of CAM unless asked makes it necessary for every oncologist to routinely ask his/her cancer patients whether they use CAM, the patterns they use, and the reasons they use them.

There were several limitations to our study. Our sample size of 121 was small. We were not able to generalize to the entire cancer population because we limited the study sample to patients who were receiving treatment at our teaching hospital. However, a national cancer registry-based study would fully describe differences in behavior that may be linked to specific demographic characteristics.

\section{Conclusion}

The prevalence of CAM use in cancer patients in rural area of China is one of the highest in the world. Chinese medicines and specified folk remedies, and faith healing/prayer house healing are the most common forms of CAM. Most of the cancer patients expected to be cured by using CAM. Some of the patients who used CAM were not willing to mention that information to their doctors. We believe that clinical oncologists should be aware of the prevalence of use of CAM in his/her environment. Patients should routinely be asked about CAM use as part of every cancer patient's evaluation.

\section{Acknowledgments}

This study was supported by State Key Basic Research and Developing Program of China (973 Program, Grant 2009CB521704) and National High-tech Research \& Developing Program of China (863 Program Grant 2006AA02A245).

\section{References}

1. Ben-Arye, E.; Karkabi, S.; Shapira, C.; Schiff, E.; Lavie, O. and Keshet, Y. (2009) Complementary medicine in the primary care setting: Results of a survey of gender and cultural patterns in Israel. Gend Med, 6:384-97.

2. Bernstein, B.J. and Grasso, T. (2001). Prevalence of complementary and alternative medicine use in cancer patients. Oncology, 15:1267-1272.

3. Cassileth, B.R.; Schraub, S.; Robinson, E. and Vickers, A. (2001). Alternative medicine use worldwide. Cancer, 91:1390-1393.

4. Chen, Z.; Gu, K.; Zheng, Y.; Zheng, W.; Lu, W. and Shu, X.O. (2008). The use of complementary and alternative medicine among Chinese women with breast cancer. J Altern Complement Med, 14:1049-55.

5. Cui, Y.; Shu, XO.; Gao, Y.; Wen, W.; Ruan, Z.X.; Jin, F. and Zheng, W. (2004). Use of complementary and alternative medicine by chinese women with breast cancer. Breast Cancer Res Treat, 85:263-70.

6. Ernst, E. (1995). Complementary cancer treatments: Hope or hazard? Clin Oncol, 7:259-263.

7. Ernst, E. and Cassileth, B.R. (1998). The prevalence of complementary/alternative medicine in cancer: A systematic review. Cancer, 83:777-782. 
8. Ernst, E.; Resch, K.L.; Mills, S.; Hill, R.; Mitchell, A.; Willoughby, M. and White, A. (1995). Complementary medicine a definition. Br J Gen Pract, 45:506.

9. Fan, R. and Holliday, I. (2007) Which medicine? Whose standard? Critical reflections on medical integration in China. J Med Ethics, 33:454-61.

10. Jordan, M.L. and Delunas, L.R. (2001). Quality of life and patterns of nontraditional therapy use by patients with cancer. Oncol Nurs Forum, 28:1107-1113.

11. Kelly, K.M.; Jacobson, J.S.; Kennedy, D.D.; Braudt, S.M.; Mallick, M. and Weiner, M.A. (2000). Use of unconventional therapies by children with cancer at an urban medical center. J Pediatr Hematol Oncol, 22:412-416.

12. Molassiotis, A. and Cubbin, D. (2004). 'Thinking outside the box': complementary and alternative therapies use in paediatric oncology patients. Eur J Oncol Nurs, 8:50-60.

13.National Center for Complementary and Alternative Medicine. Available on-line at: http://nccam.nih.gov/health/whatiscam/ (17 June 2004, date last accessed).

14. Oneschuk, D.; Fennell, L.; Hanson, J. and Bruera, E. (1998). The use of complementary medications by cancer patients attending an outpatient pain and symptom clinic. J Palliat Care, 14:21-26.

15. Patterson, R.E.; Neuhouser, M.L.; Hedderson, M.M.; Schwartz, S.M.; Standish, L.J.; Bowen, D.J. and Marshall, L.M. (2002). Types of alternative medicine used by patients with breast, colon, or prostate cancer: predictors, motives, and costs. J Altern Complement Med, 8:477-485.

16. Richardson, M.A.; Sanders, T.; Palmer, J.L.; Greisinger, A. and Singletary, S.E. (2000). Complementary/alternative medicine use in a comprehensive cancer center and the implications for oncology. J Clin Oncol, 18:2505-2514.

17. Roth, M.A. and Kobayashi, K.M. (2008) The use of complementary and alternative medicine among Chinese Canadians: results from a national survey. J Immigr Minor Health, 10:517-28.

18. Sparber, A.; Bauer, L.; Curt, G.; Eisenberg, D.; Levin, T.; Parks, S.; Steinberg, S.M. and Wootton, J. (2000). Use of complementary medicine by adult patients participating in cancer clinical trials. Oncol Nurs Forum, 27:623-630.

19. Sparber, A. and Wootton, J.C. (2001). Surveys of complementary and alternative medicine: part II. Use of alternative and complementary cancer therapies. J Altern Complement Med, 7:281-287.

20. Swisher, E.M.; Cohn, D.E.; Goff, B.A.; Parham, J.; Herzog, T.J.; Rader, J.S. and Mutch, D.G. (2002). Use of complementary and alternative medicine among women with gynecologic cancers. Gynecol Oncol, 84:363-367. 